\title{
The Role of Gesture in the Second Language Learning and Teaching
}

\author{
${ }^{1}$ Ning Cao and ${ }^{2}$ Guanying Chen \\ ${ }^{1}$ Department of Learning and Instructions, \\ University at Buffalo, State University of New York, Buffalo, NY 14260, USA \\ ${ }^{2}$ School of Chemistry and Chemical Engineering, \\ Harbin Institute of Technology, Harbin, Heilongjiang 150001, China
}

Article history

Received: 11-10-2017

Revised: $27-12-2017$

Accepted: 30-12-2017

Corresponding Author:

Ning Cao

Department of Learning and Instructions, University at Buffalo, State University of New York, Buffalo, NY 14260, USA

Email: ningcao@buffalo.edu

\begin{abstract}
This paper outlines the crucial role of gesture in the second Language (L2) learning and teaching. Many studies showed that gesture is a key factor in the second language acquisition since it can help to convey meaning, to compensate for speech difficulties and to enhance memory compared to pure verbal learning. The presence of gestures with a verbal message in L2 learning brings a positive outcome to both speakers and listeners. Studies showed that gestures not only facilitate L2 learners in second language listening comprehension, but also have a crucial impact on the L2 word learning. Also, gestures are used as effective teaching strategies in L2 teaching and classroom management. Thus, gesture as a facilitating educational tool in second language learning deserves both L2 learner and teacher's further attentions.
\end{abstract}

Keywords: Gesture, Language, L2 Learning, L2 Teaching

\section{Introduction}

Gesture refers to any of a variety of movements, including movement of hands and arms, adjustment of posture, touching of oneself (e.g., stroking one's hair), various (nervous) ticks and other fiddling movements that people use while talking (Kendon, 1996). Therefore, gestures constitute a central feature of human development, knowing, learning and communication and there is a close link between gestures and speech. As we know, more and more studies state that language consists of both speech and gesture forming one "composite signal" (McNeill, 1992). Under this view, language acquisition and learning entail the acquisition of gestures as much as of speech.

As a form of input to learners and to their interlocutors alike, gestures also play a potential role for comprehension and learning (Gullberg, 2006). Based on Maranne's study, gestures can be treated as part of what learners can acquire in a target language. Gestures can, therefore, be studied as a developing system in their own right in the second Language (L2) both production and comprehension (Gullberg, 2006). Also, learners' gestures as deployed in L2 usage and interaction can offer valuable insights into the processes of acquisition, such as the handling of expressive difficulties, the influence of the first language, inter-language phenomena and possibly even into planning and processing difficulties (Gullberg, 2006).

The purpose of this review is to make an argument for the importance of studying gesture and its relation to speech in L2 educational settings, trying to find the role of gesture in L2 learning. It will review the research literature and provide an opinion of the use of gestures in the second language learning and acquisition among L2 students.

\section{The Role of Gestures in Second Language Learning}

Second-language learning or L2 acquisition is the process by which people learn a second language. Some research found that some internal factors, such as age, personality, motivation, experiences and cognition, determine the speed and facility with which the new language is learned. It is also found that people make use of gestures as a tool when they try to express themselves in a foreign language. The gestures help to convey meaning and to compensate for speech difficulties (Goldin-Meadow, 2003), if gesture is performed during learning of words and phrases, they enhance memory compared to pure 
verbal encoding (Zimmer et al., 2001); therefore, gestures, as the nonverbal behaviors must be considered as a key factor in second language acquisition.

Gesture can often serve as an involuntary teacher; the speaker does not intend to explain, but the concrete gestural representation of the utterance might allow a less informed listener to guess the meaning of words unknown to him (Calbris, 1990). A majority of speakers' gestures are produced at the same time as spoken words that possess similar meaning. However, gestures are not completely redundant with the speech, as they often represent abstract ideas that cannot be expressed by speech alone (Kita and Özyürek, 2003). Researchers have debated to what extent gestures and speech are dependent on each other and to what extent they are separable (McNeill, 1992). The use of gestures with a verbal message brings a positive outcome to both L2 speakers and listeners. Some studies found that those learning English as a second language have the benefit of greater exposure to nonverbal communication features such as gestures (Manuela et al., 2011).

Many researchers have found that L2 speakers tend to produce more gestures in L2 than in L1 (Gullberg, 1998). In L2 classroom, gesture and speech are closely related in the process of L2 teaching and learning, because L2 learners usually use gestures as scaffolding and speech-related gestures to help promote and facilitate learning the second language better and faster.

In Hams (2003)'s study, it pointed out, speech-related gestures seem to complement the spoken word. These gestures are directly tied to the lexical affiliate and form part of the speaker's communicative intention (Hams, 2003). Also, it was demonstrated that such gestures may assist in the decoding of speech at the "while-listening" stage of L2 listening comprehension. Similar to Tony's study, Ayano and Debra (2005) investigated the contribution of gestures and facial cues to secondlanguage learners' listening comprehension by a native speaker of English. It assesses the contribution of gestures and facial cues (e.g., lip movements) to listening comprehension by low-intermediate and advanced learners of English as a Second Language (ESL). Results showed that, for the lower level, AVgesture-face (audiovisual including gestures and face) produced the highest scores and showed the best results (Ayano and Debra, 2005).

In fact, gestures not only facilitate L2 learners in second language listening comprehension, but also have a crucial impact on the L2 word learning. One reason is that words learned with gesture produced a larger Late Positive Complex (indexing recollection) in bi-lateral parietal sites than words learned without gesture (Kelly et al., 2009). Actually, vocabulary acquisition represents a major challenge in foreign language learning. Research has demonstrated that gestures accompanying speech have an impact on memory for verbal information in both the speakers' mother tongue and the second language learning. Recent studies have demonstrated that iconic gestures enhance foreign language learning. Some studies show that the use of gestures during word learning facilitates new vocabulary retrieval in both children (Tellier, 2008) and adults (Kelly et al., 2009). Similarly, in Manuela et al. (2011)'s study, it confirmed the close relationship between gesture and language and extended to word learning in a foreign language. It was found that iconic gestures produce significantly better memory performance on the word learning of a foreign language than meaningless gestures. Tellier (2008) also pointed out that reproducing the gestures while repeating the words enables children to memorize vocabulary better in L2, as they can get physically involved in their learning.

Mccafferty (2002) analyzed how gesture is linked to speech in creating zones of proximal development. He examined videotapes of one adult native speaker and one adult non-native speaker of English in informal interactions with one another. He found that gestures are not only implicated in lexical comprehension, but also in illustrations, environmental referents and imitation. He concluded that not only do gestures promote language learning, but they engender a "positive interaction between the two participants, helping to create a sense of shared social, symbolic, physical and mental space.

Yoshioka and Kellerman (2006) stated that, in the field of Second Language Acquisition (SLA) and use, learners' gestures have mainly been regarded as a type of communication strategy produced to replace missing words. Gullberg (1998) also investigated the use of gestural communication strategies, as opposed to oral communication strategies, by foreign language speakers of French and Swedish. She concluded that complementary strategic gestures were used more frequently than substitutive strategic gestures in FL/L2. Also, foreign language speakers appeared to favor a combination of the two types of strategies-oral and gestural - more than the L1 speakers did. Gullberg (1998) confirmed the increase in the use of gestures by foreign language speakers on the whole and as communication strategies, acknowledging differences between the individuals in the amount and types of gestures used.

\section{The Role of Gestures in Second Language Teaching}

Although these studies have shed some light on the role of gesture in L2 learning, they do little to explicate teacher's gesture in L2 classroom setting. In L2 classroom, teachers behave in a specific way, teacher usually use helping gestures so as to be sure the students will understand them better. The gesture used by L2 teacher in second language teaching is different 
from everyday communicative gesture, sometimes, the gestures are what the learners rely on to understand what the teacher says.

Goldin-Meadow (2003) pointed out that "gesture serves as both a tool for communication for listeners and a tool for thinking for speakers"'. For speakers, gestures facilitate retrieval of words from memory and reduce cognitive burden. For listeners, they can facilitate comprehension of a spoken message and convey thoughts not present in speech (Goldin-Meadow, 2003). As we know, gesture can act as a vehicle for promoting learning, it can also play a role in conveying knowledge in both direct and indirect ways.

In the early studies, literature in L2 education provides many examples in which nonverbals are used as effective teaching strategies and in classroom management. Based on the prior studies, nonverbal, especially gestures, may be used to: (1) Vary the tempo, (2) control participation, (3) signal changes, (4) indicate who is to respond, (5) cue choral response, (6) mark beginnings and ends of lessons and (7) give students an idea of what to expect (Ward and Raffler-Engel, 1980). Barnett suggested that teachers develop a standard set of hand or arm gestures so as to promote students' learning (Barnett, 1983). For example, the teacher's swinging the arm upward could cue the students to form a question while swinging the arm downward requests a response. Also, some other signals may indicate when students should listen, repeat, answer or to speak louder.

In the recent study of Sime (2006), it investigated how learners in an EFL class make sense of teachers' gestures and other nonverbal behaviors. The researcher suggested that one of the crucial things that L2 learners learn in a language classroom was how to interpret teachers' gestures in conjunction with their verbal input in order to learn successfully. Findings indicated that learners generally believed that gestures and other non-verbal behaviors played a key role in the language learning process. Learners identified three types of functions that gestures play in EFL classroom interaction: (i) Cognitive, i.e., gestures which work as enhancers of the learning processes, (ii) emotional, i.e., gestures that function as reliable communicative devices of teachers' emotions and attitudes and (iii) organizational, i.e., gestures which serve as tools of classroom management. These findings suggested that learners interpret teachers' gestures in a functional manner and use these and other non-verbal messages and cues in their learning and social interaction with the teacher (Sime, 2006).

Echo to Sime (2006)'s study, in second language classroom, the teacher instinctively use gesture, along with some words, paraphrases and sentences, with an attempt to make the L2 students learn a second language better. Lazaraton (2004)'s study explored teacher's nonverbal behaviors in classroom discourse by analyzing the gestures, speech and other nonverbal behaviors that one ESL teacher employs in her vocabulary explanations in the classroom. It is found that the ESL teacher used a variety of gestures in giving vocabulary explanations for 18 lexical terms. It is claimed that classroom L2 learners receive considerable input in nonverbal form that may modify and make verbal input more comprehensible (Lazaraton, 2004).

\section{The Relationship between the Use of Gesture and L2 Proficiency}

Most of the studies investigating L2 learners' use of gestures examined the relationship between L2 language proficiency and the number of gestures used, also, they infer some possible relationships between proficiency level and use of specific types of gestures among L2 learners.

Based on Nobe's study, adult foreign language learners use more gestures than the native speakers and foreign language speakers' moments of difficulty in expressing themselves are accompanied by a correspondent increase in the amount and frequency of gestures (Nobe, 1993). Also, Stam (1999) considered proficiency as a determinant factor, suggesting that at advanced levels of proficiency the cognitive load on linguistic representations becomes relatively lighter and this decreases the amount of gestures produced by a speaker. Similarly, Tammy et al. (2009) also examined the possible connections between second language competency and frequency and type of gesture use (illustrators, compensatory illustrators, adaptors, emblems, regulators and affect displays). The results of this study showed that learners at higher levels of language proficiency are more likely to use gestures that enhance the meaning of the verbal message and contribute to greater communicative competence than their less proficient counterparts. What's more, it indicated that advanced learners used significantly more speech-related, meaning-enhancing gestures than did beginning and intermediate students and that participants used significantly more gestures overall in their native English than they did in the target language (Spanish) (Tammy et al., 2009).

Since there are different categories of gestures, a question raises naturally, is there any relationship between the various kinds of gestures and language proficiency? Some study showed that the children used more conventional and deictic gestures without speech to communicate in their weaker language while symbolic gestures were not used more frequently in the children's stronger language (Nicoladis, 2002). However, the strong connection between symbolic gestures and language proficiency is not limited to children. Gullberg 
(1998) reported that intermediate second language learners ( 5 with French as their first language and 5 with Swedish as their first language) used more symbolic gestures when retelling a story in their first language than in their second language. In contrast, the speakers used more deictic gestures in their second language. Gullberg (1998) found that this category of gesturing held a variety of very important functions. This gesture-type primarily co-occurred with grammatical, not lexical difficulties and used space to indicate temporal properties such that, by pointing to a certain spot, an idea of tense could be expressed (Gullberg, 1998). For example, with L2 production, participants occasionally had difficulty expressing past tense verbs. By pointing to the left of an invisible median axis running down the length of the speaker's body, the implication of past tense was passed on to the listener, while the present tense was verbally expressed by the speaker.

Similar to prior studies, Jody and Elena (2005) examined the role of deictic (i.e., point) and symbolic (i.e., imagistic) gestures in advanced Spanish-English second-language learners to determine whether the role of gestures is consistent with that of intermediate second language learners. It is found that the results from this study support the idea that different kinds of gestures might be related to speech in different ways. Deictic gestures may increase when proficiency is weak, that is, participants used more deictic gestures in their second language. Contrary to research with low or intermediate proficiency participants, however, symbolic gestures did not appear related to proficiency. Furthermore, except for L2 proficiency, some studies found that culture also plays a significant role in the use of gesture. Smithson et al. (2011) states cultural norms of gesture frequency may be more important in explaining how frequently gestures are used.

\section{Conclusion}

In general, gestures play a significant role in L2 learning and teaching, gestures and other nonverbal behaviors are the forms of input to the second language learners that must be considered as a salient factor in second language acquisition research. More and more studies have shown that the presence of gestures with a verbal message brings a positive outcome to both L2 learners and teachers. Actually, in L2 classroom, gesture and speech are closely related in the process of L2 teaching and learning and the speech-related gestures help to promote and facilitate L2 learners learning the second language better. Gestures have been used as effective teaching strategies and in classroom management.

These findings will definitely give some practical and theoretical implication to educators and researchers who aim to conduct a study on speech and gestures in a second language learning setting. It would remind L2 teachers that they need to become more reflective in their gestures so as to support L2 learners to make a better use of teacher's gestures in the process of L2 learning.

Since linguistic and cultural experience as well as proficiency level are crucial factors influencing the information value of the use of gestures in a speech event; further studies on the speech and gesture are encouraged to consider more cultural factors. The other forms of nonverbal communications also should be considered so as to facilitate L2 comprehension and raise L2 learners' awareness to them. Also, the gestural competence displayed by the L2 teachers deserves further attention.

\section{Acknowledgement}

Ning Cao would like to thank the discussions and guidance from Dr. Vladimir Ageyev.

\section{Author's Contributions}

Ning Cao: Organize and draft the whole manuscript.

Guanying Chen: Edit the language and provide valuable discussions on the content and structure.

\section{Ethics}

The authors would like to acknowledge that Dr. Guanying Chen is the Editor in Chief of American Journal of Applied Sciences.

\section{References}

Ayano, S. and M.H. Debra, 2005. The role of gestures and facial cues in second language listening comprehension. Lang. Learn., 55: 661-669. DOI: $10.1111 /$ j.0023-8333.2005.00320.x

Barnett, M.A., 1983. Replacing teacher talk with gestures: Nonverbal communication in the foreign language classroom. Foreign Lang. Annals, 16: 173-176.

DOI: $10.1111 /$ j. 1944-9720.1983.tb01446.x

Calbris, G., 1990. The Semiotics of French Gestures. 1st Edn., Indiana University Press, Bloomington, ISBN-10: 0253312973, pp: 236.

Goldin-Meadow, S., 2003. Hearing Gesture: How our Hands Help us Think. 1st Edn., Belknap Press of Harvard University Press, Cambridge, Mass., ISBN-10: 0674010728, pp: 280.

Gullberg, M., 2006. Some reasons for studying gesture and second language acquisition (Hommage à Adam Kendon). Int. Rev. Applied Linguist., 44: 103-124. DOI: 10.1515/IRAL.2006.004 
Gullberg, M., 1998. Gesture as a Communication Strategy in Second Language Discourse: A Study of Learners French and Swedish. 1st Edn., Lund University Press, Lund, ISBN-10: 917966508X, pp: 253.

Hams, T., 2003. Listening with your eyes: The importance of speech-related gestures in the language classroom. Foreign Lang. Annals, 36: 180-187. DOI: 10.1111/j.1944-9720.2003.tb01468.x

Jody, S. and N. Elena, 2005. Gestures by advanced Spanish-English second-language learners. Gesture, 4: 143-156. DOI: 10.1075/gest.4.2.03she

Kelly, S.D., T. McDevitt and M. Esch, 2009. Brief training with co-speech gesture lends a hand to word learning in a foreign language. Lang. Cognitive Process, 24: 313-334. DOI: $10.1080 / 01690960802365567$

Kendon, A., 1996. An agenda for gesture studies. SemioticReview, 7: 1-22.

Kita, S. and A. Özyürek, 2003. What does crosslinguistic variation in semantic coordination of speech and gesture reveal?: Evidence for an interface representation of spatial thinking and speaking. J. Memory Lang., 48: 16-32. DOI: $10.1016 / \mathrm{S} 0749-596 \mathrm{X}(02) 00505-3$

Lazaraton, A., 2004. Gesture and speech in the vocabulary explanations of one ESL teacher: A microanalytic inquiry. Lang. Learn., 54: 79-117. DOI: $10.1111 /$ j.1467-9922.2004.00249.x

Manuela, M., M. Karsten and D.F. Angela, 2011. The impact of iconic gestures on foreign language word learning and its neural substrate. Human Brain Mapp., 32: 982-998. DOI: 10.1002/hbm.21084

Mccafferty, S.G., 2002. Gesture and creating zones of proximal development for second language learning. Modern Lang. J., 86: 192-203.

DOI: $10.1111 / 1540-4781.00144$

McNeill, D., 1992. Hand and Mind: What Gestures Reveal about Thought. 1st Edn., University of Chicago Press, Chicago, ISBN-10: 0226561321, pp: 416.

Nicoladis, E., 2002. Some gestures develop in conjunction with spoken language development and others don't: Evidence from bilingual preschoolers. J. Nonverbal Behav., 26: 241-266.

DOI: $10.1023 / \mathrm{A}: 1022112201348$
Nobe, S., 1993. Cognitive processes of speaking and gesturing: A comparison between first language speakers and foreign language speakers. MSc Thesis, University of Chicago.

Sime, D., 2006. What do learners make of teachers' gestures in the language classroom? Int. Rev. Applied Linguist. Lang. Teach., 44: 211-230. DOI: 10.1515/iral.2006.009

Smithson, L., E. Nicoladis and P. Marentette, 2011. Bilingual children's gesture use. Gesture, 11: 330-347. DOI: 10.1075/gest.11.3.04smi

Stam, G., 1999. Speech and gesture: What changes first in L2 acquisition. Proceedings of the 2nd Language Research Forum, (LRF' 99), University of Minneapolis.

Tammy, G., G. Olivares-Cuhat and S. John, 2009. An examination of L1 and L2 gesture use: What role does proficiency play? Modern Lang. J., 93: 195-208. DOI: $10.1111 /$ j.1540-4781.2009.00856.x

Tellier, M., 2008. The effect of gestures on second language memorisation by young children. Gesture, 8: 219-235. DOI: 10.1075/gest.8.2.06tel

Ward, L. and W. Raffler-Engel, 1980. The impact of nonverbal behavior on FL teaching. Aspects NonVerbal Behav.

Yoshioka, K. and E. Kellerman, 2006. Gestural introduction of ground reference in L2 narrative discourse. Int. Rev. Applied Linguist. Lang. Teach., 44: 173-195. DOI: 10.1515/IRAL.2006.007

Zimmer, H., 2001. Why do Actions speak louder than words. Action memory as a variant of encoding manipulations or the result of a specific memory system?

Zimmer, H.D., R.L. Cohen, M.J. Guynn, J. Engelkamp and R. Kormi-Nouri et al., 2001. Memory for Action: A Distinct form of Episodic Memory. 1st Edn., Oxford University Press, New York, ISBN-10: 0195353978, pp: 224. 